\title{
RESEARCH
}

Open Access

\section{Effects of 405-, 532-, 650-, and 940-nm wavelengths of low-level laser therapies on orthodontic tooth movement in rats}

\author{
Hasibe Baser Keklikci ${ }^{*}$, Ahmet Yagci², Arzu Hanim Yay ${ }^{3,4}$ and Ozge Goktepe ${ }^{3}$
}

\begin{abstract}
Background: Investigating the effects of 405-nm, 532-nm, 650-nm, and 950-nm wavelengths of LLLTs (low-level laser therapies) on the orthodontic tooth movement in rats by using histological and immunohistochemical methods. Forty-five Wistar albino rats were randomly divided into 5 groups: control group (positive control: the left maxillary 1st molar side; negative control: the right maxillary 1st molar side), $405 \mathrm{~nm}$ LLLT group (Realpoo), $532 \mathrm{~nm}$ LLLT group (Realpoo), $650 \mathrm{~nm}$ LLLT group (Realpoo), and $940 \mathrm{~nm}$ LLLT group (Biolase). The left maxillary 1st molar teeth of all rats were applied mesially 50-g force. Starting from the 1st day, $48 \mathrm{~h}$ intervals, LLLT was applied in continuous wave mode and in contact with the tissue. The application area was approximately $1 \mathrm{~cm}^{2}$. The lasers were performed for 3 min on each surface (buccal, palatal, mesial), totally 9 min (total dose $54 \mathrm{~J} / \mathrm{cm}^{2}$ ). The amount of the molar mesialization, the bone area between the roots, PDL (periodontal ligament) measurements, TRAP (tartrate-resistant acid phosphatase), and ALP (alkaline phosphatase) immunoreactivity intensity were calculated.

Results: The amount of the molar mesialization was significantly higher in the $650 \mathrm{~nm}$ LLLT group (mean $0.878 \pm$ $0.201 \mathrm{~mm} ; 95 \% \mathrm{Cl}$ (confidence interval) 0.724 and 1.032) than in the groups of positive control (mean $0.467 \pm 0.357$ $\mathrm{mm} ; 95 \% \mathrm{Cl} 0.192$ and 0.741 ) and $405 \mathrm{~nm} \mathrm{LLLT}$ (mean $0.644 \pm 0.261 \mathrm{~mm} ; 95 \% \mathrm{Cl} 0.443$ and 0.845$)(p<0.001)$. There were significant differences in the PDL-mesial $(p=0.042)$ and PDL-distal $(p=0.007)$ regions between the groups. The immunoreactivity intensity for TRAP-mesial was significantly higher in the positive control group (mean 109, $420.33 \pm 8769.17 ; 95 \% \mathrm{Cl} 100,217.65$ and 118,623.02) than in the $405 \mathrm{~nm}$ (mean 91,678.83 $\pm 7313.39 ; 95 \% \mathrm{Cl} 84,003.9$ and 99,353.77) and the $650 \mathrm{~nm} \mathrm{LLLT} \mathrm{(mean} \mathrm{87,169.17} \pm$ 4934.65; 95\% Cl 81,990.56 and 92,347.77) groups ( $p=0.002$ ). There was no statistically significant difference between the groups on immunoreactivity intensity with ALP staining.

Conclusions: The results of this study show that LLLT with 650-nm wavelength increases orthodontic tooth movement more than 405-nm, 532-nm, and 940-nm LLLTs. The 940-nm and 650-nm LLLTs also increase the bone area between the roots by more than $405-\mathrm{nm}$ and 532-nm wavelengths.
\end{abstract}

Keywords: Low-level laser therapy (LLLT), Accelerated orthodontic tooth movement, TRAP, ALP

\footnotetext{
* Correspondence: hasibebaser91@gmail.com

${ }^{1}$ Eskisehir Oral and Dental Health Hospital, Yenikent, Piri Reis St. No. 28, Odunpazarı, 26050 Eskisehir, Turkey

Full list of author information is available at the end of the article
}

\section{Springer Open}

(c) The Author(s). 2020 Open Access This article is licensed under a Creative Commons Attribution 4.0 International License, which permits use, sharing, adaptation, distribution and reproduction in any medium or format, as long as you give appropriate credit to the original author(s) and the source, provide a link to the Creative Commons licence, and indicate if changes were made. The images or other third party material in this article are included in the article's Creative Commons licence, unless indicated otherwise in a credit line to the material. If material is not included in the article's Creative Commons licence and your intended use is not permitted by statutory regulation or exceeds the permitted use, you will need to obtain permission directly from the copyright holder. To view a copy of this licence, visit http://creativecommons.org/licenses/by/4.0/. 


\section{Background}

For the patients who have an indication for orthodontic treatment, the biggest concerns are the long duration of the therapy and the pain they will suffer during this process [1]. The prolongation of the orthodontic treatment period may lead to many undesirable conditions such as reduced patient cooperation, caries formation, periodontal diseases, and root resorption. Therefore, researchers are working on methods that will accelerate orthodontic tooth movement and shorten the duration of treatment.

In the literature, the methods that accelerate tooth movement are under four main headings as traditional orthodontic biomechanical methods, surgical, chemical, and physical applications [2]. Because the effect of traditional orthodontic methods on accelerating tooth movement is limited, surgical-assisted methods require an invasive procedure and may be painful, and chemical methods show systemic side effects other than their local effects; clinicians tend to be more interested in physical methods $[3,4]$. Because it is easy to apply and requires only a few equipments, LLLT (low-level laser therapy) is one of the most popular techniques among them.

LLLT is considered to be effective in controlling pain, modulating inflammation, accelerating the growth of new tissue, and increasing wound healing. When light enters the tissue and is absorbed, biochemical processes are triggered that lead to the activation of the mitochondrial chain and then mainly to the increase in the production of ATP (adenosine triphosphate), NO (nitric oxide), and a small amount of ROS (reactive oxygen species). As a result, LLLT accelerates the activities on a cell and affects the process on the tissue level [5]. The laserinduced analgesia is thought to operate on a variety of local and systemic pathways including the inhibition of axonal depolarization; selective reduction of acute inflammatory mediators such as prostaglandins, IL1- $\beta$ (Interleukin 1 beta), IL-6 (Interleukin 6), and TNF- $\alpha$ (tumor necrosis factor alpha); vasodilatation; and improved lymphatic drainage [6].

Receptor activator of nuclear factor kappa-B ligand (RANKL) and its receptor RANK (receptor activator of nuclear factor kappa-B) present a regulatory function in bone homoeostasis [7]. The available limited evidence suggests that LLLT increases the expression of both RANK and RANKL [8] and may have a role in accelerating orthodontic tooth movement [9-11].

Besides the studies showing that LLLT accelerates the movement of the teeth $[12,13]$, there are also the ones that conclude it slows down the shift [14] or the effect of LLLT is insignificant [15]. In many studies, different doses or different application times of the same wavelength laser were investigated. In few ones, two different wavelengths were applied in the same particular research, but many parameters such as application mode, power density, energy density, frequency of application, and experimental period of lasers vary between the experimental groups. Therefore, the interpretation of these results is a complex work, and it is not possible to compare the statistics of these studies with each other in a healthy analytic manner.

To accelerate tooth movement and shorten the duration of orthodontic treatment, it is very important to understand tooth movement histologically and immunohistochemically. In orthodontic tooth movement, a high rate of TRAP (tartrate-resistant acid phosphatase) concentration is observed in destructive cells in bone and root resorption areas [16]. TRAP is an enzyme secreted from osteoclasts during active bone destruction. Therefore, TRAP staining is used to identify resorptive cells that cannot be identified by routine histological staining in orthodontic tooth movement and orthodontic root resorption [17]. ALP (alkaline phosphatase) indicates osteoblastic activity during bone formation. ALP is produced at very high concentrations during the construction phase of the bone cycle and provides a good idea of the overall bone-building activity.

\section{Methods}

The aim of this study is to investigate the effects of lowlevel lasers of the 405-nm, 532-nm, 650-nm, and 940$\mathrm{nm}$ wavelengths, on the tooth movement rate by using histological and immunohistochemical methods.

The number of animals to be used was determined as $90 \%$ power and $p=0.05$ impacts according to power analysis, and a total of 45 subjects in each group 9 subjects. Forty-five Wistar albino rats (8 weeks old; weight, $140.98 \pm 12.86 \mathrm{~g}$ ) were in polycarbonate cages at an average temperature of $22 \pm 2{ }^{\circ} \mathrm{C}, 12 \mathrm{~h}$ light and $12 \mathrm{~h}$ dark. They were fed ad libitum with a standard laboratory diet and tap water. No food restriction was made.

\section{Groups}

Rats were divided into five study groups randomly: control group, $405 \mathrm{~nm}$ LLLT group, $532 \mathrm{~nm}$ LLLT group, $650 \mathrm{~nm}$ LLLT group, and $940 \mathrm{~nm}$ LLLT group. In the control group, only experimental tooth movement was created, and no laser application was performed. In the control group, the left maxillary 1st molars were used as a positive control (PC) group and the right maxillary 1st molars were used as a negative control (NC) group (Fig. 1).

\section{Experimental tooth movement}

To obtain experimental tooth movement, nickel-titanium closed-coiled springs were placed between the maxillary incisor teeth and the left maxillary 1st molar teeth of the rats to apply 50-g force. The experiment period was 14 days. No activation was made for the tooth movement 


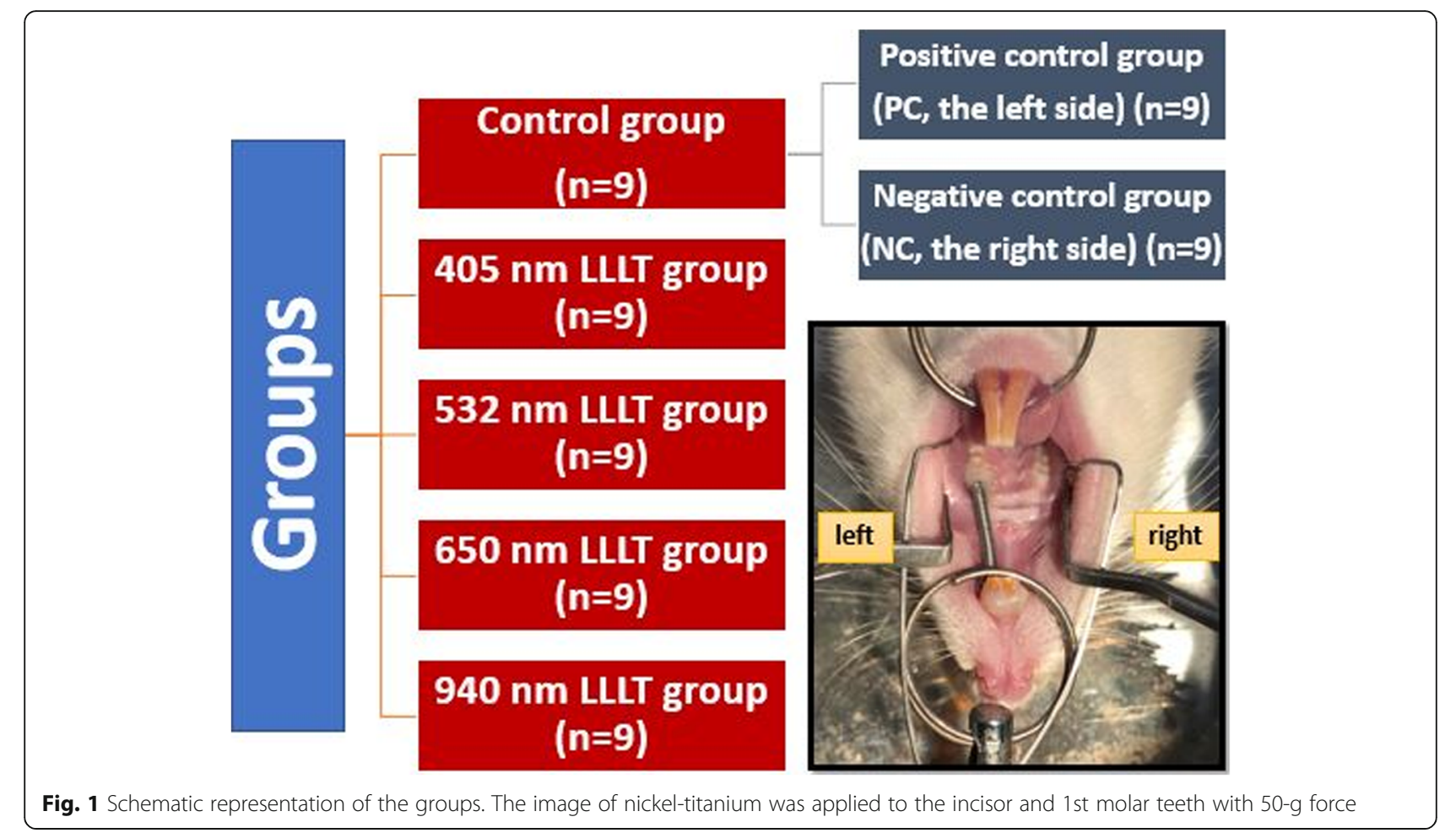

during the experimental period; only the robustness of the apparatus was checked (Fig. 1).

\section{Laser irradiation}

Diode laser modules (405 nm (Realpoo, RP100AD40510BD, Jilin, China); $532 \mathrm{~nm}$ (Realpoo, M532D100, Jilin, China); $650 \mathrm{~nm}$ (Realpoo, RP100AD650-10 BC, Jilin, China), and $940 \mathrm{~nm}$ (Biolase, Epic 10 ${ }^{\mathrm{TM}}$, Ingbert, Germany)) with $100 \mathrm{~mW} / \mathrm{cm}^{2}$ output power calibrated with the calibration device (Apogee Solar Radiation MP-200). Starting from the 1st day, with $48 \mathrm{~h}$ intervals, LLLT was applied in a continuous wave mode and in contact with the tissue. The application area was approximately $1 \mathrm{~cm}^{2}$. The lasers were performed for $3 \mathrm{~min}$ on each surface (buccal, palatal, mesial), totally $9 \mathrm{~min}$ (total dose $54 \mathrm{~J} / \mathrm{cm}^{2}$ ) (Fig. 2a).

\section{Anesthesia}

All operations were carried out under general anesthesia, with an intraperitoneal injection of ketamine $\mathrm{HCl}(1.0$ $\mathrm{mg} / \mathrm{kg}$; Alfamine ${ }^{\circ}$ Egevet, Turkey) and xylazine $\mathrm{HCl}$ $\left(0.5 \mathrm{mg} / \mathrm{kg}\right.$; Rompun ${ }^{\circ}$ Bayer, Leverkusen, Germany) combination. For the purpose of checking the apparatus and equalizing the stress levels of general anesthesia on animals, the control group animals were also anesthetized with $48 \mathrm{~h}$ intervals, as in the laser groups.

\section{Measurement of the tooth movement}

The distances between the incisor tooth (palatal side, gingival level) and the 1st molar tooth mesial surface (most convex point) in the maxilla were measured with a digital caliper with an accuracy of $0.01 \mathrm{~mm}$ on both the right and the left sides before the apparatus was applied (T0) and at the end of the experiment period (T1) (Fig. 2b). The measurements were repeated 3 times, and the average of these values was recorded. The difference between the left side initial length $\left(\mathrm{TO}_{\text {left }}\right)$ and the length after tooth movement $\left(\mathrm{T}_{1}\right.$ left $)$ was recorded. The same procedure was repeated for the right side. In order to determine the amount of molar mesialization, the difference in length on the right side (distal tipping amount of the incisors) was subtracted from the length difference on the left side (Fig. 3).

\section{Histological assessment}

After the sacrification of the subjects, the tissues containing the tooth samples were put in a $10 \%$ formaldehyde solution before the examination. Tissues which were kept in formaldehyde for $72 \mathrm{~h}$ were decalcified in a decalcification solution containing acetic acid and embedded in paraffin. Serial sections of 5 - $\mu \mathrm{m}$-thick were stained with Masson's trichrome for light microscopic histological examination. Images were analyzed by using a microscope (Olympus BX-51, Japan) for morphological observation of tissues. 


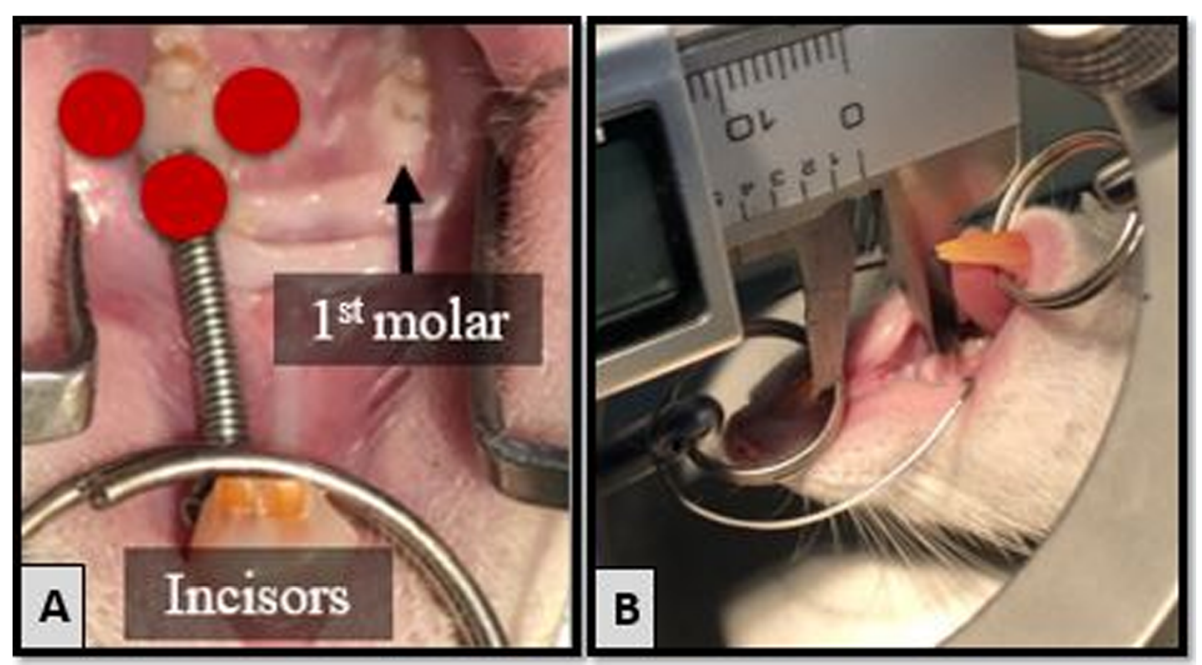

Fig. 2 a Schematic representation of low-level laser-treated areas with red circles (buccal, palatal, and mesial). b Measurement of the distance between the incisor and the 1st molar teeth with a digital caliper

For the histologic examinations, the mesial roots of the maxillary first molars were used. Images were obtained with $\times 10$ magnification via the ImageJ software (http://imagej.nih.gov/ij/; provided in the public domain by the National Institutes of Health, Bethesda, MD, USA) and recorded. In the histological sections stained with Masson trichrome, the PDL distance between the root and the alveolar bone of the mesial root of the maxillary 1st molar tooth was measured from the cervical in the mesial (PDL-M; pressure side) and distal (PDL-D; tension side) regions of the root. In the same sections, the bone area between the mesial and mesiopalatinal roots of the maxillary 1st molar tooth was calculated by marking at 10X magnification with the ImageJ software program in the region that passes through the most apical points of the roots [18].

\section{Immunohistochemistry}

In this study, the expression of TRAP and ALP in mesial root tissue of the maxillary 1st molar tooth was demonstrated immunohistochemically. Paraffin-embedded ovarian tissue sections of 5 - $\mu \mathrm{m}$-thick were dehydrated first in xylene and next in graded ethanol solutions. The slides were then blocked with $5 \%$ bovine serum albumin in phosphate-buffered saline (PBS) for $2 \mathrm{~h}$. Then, IHC staining was performed by a standard avidin-biotinperoxidase procedure by using the Ultravision Polyvalent (Rabbit-Mouse) Horseradish Peroxidase (HRP) Kit, $125 \mathrm{ml}$ from Thermo Fisher Scientific (Waltham, MA, USA). The sections were incubated with TRAP (rabbit anti-TRAP/ TRAP polyclonal antibody from Abcam (Cambridge, MA, USA)) and ALP (anti-ALP antibody, $100 \mathrm{ml}$ from Abcam (Cambridge, MA, USA)) primary antibodies, overnight at

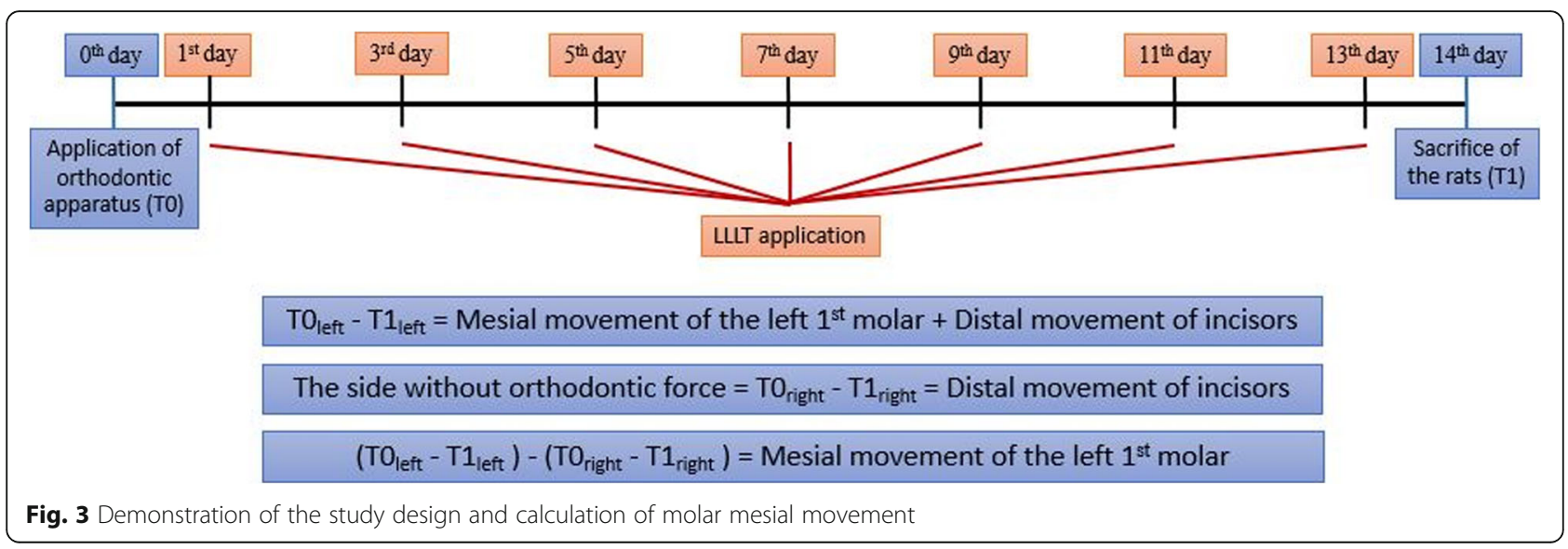


$4{ }^{\circ} \mathrm{C}$. After rinsing thoroughly with PBS, the sections were incubated with a biotinylated secondary antibody; after that, the horseradish peroxidase-conjugated streptavidin solution was added and incubated at room temperature for $10-15 \mathrm{~min}$. Finally, the sections were visualized with diaminobenzidine substrate (DAB) (diaminobenzidine chromogen and substrate system, $125 \mathrm{ml}$ from Thermo Fisher Scientific (Waltham, MA, USA)) as chromogen for 3-5 min at room temperature. Counterstaining was performed using hematoxylin, and the slides were visualized under a light microscope. The slides were processed immunohistochemically at the same laboratory conditions in order to obtain comparable staining intensities.

\section{Quantitative immunohistochemistry}

The digital color images were registered using a light microscope (Olympus BX-51, Japan) equipped with a camera (DP 71) and connected to a computer at $\times 10$ and $\times 20$ magnification from the mesial root region of the maxillary 1st molar tooth. Then, the quantification of the TRAP and ALP immunoreactivity intensity was calculated in both the mesial and the distal PDL regions where the middle of the root up to the cervical bone, and the results were recorded. Because we think that the laser we applied may not reach the apical region, we measured only the cervical half of the root. In our study, the cervical semi-pressure region in the mesial root in the mesial and the cervical half in the distal of the mesial root was used as the tension zone (Fig. 4).

\section{Statistical analysis}

All of the data were transferred to SPSS 24.0 (SPSS Inc., Chicago, IL, USA) and prepared for the analysis. The normality of the variables was determined by using the Shapiro-Wilk test and homogeneities by using the Levene test. The data of PDL length, orthodontic tooth movement, and the bone area between the roots were evaluated using the non-parametric test, and the Kruskal-Wallis test was used for comparisons between the groups. The Mann-Whitney $U$ test was used for the parameters which were statistically significant. $p<0.05$ was considered statistically significant. The one-way ANOVA test was used for the analysis of TRAP and ALP immunoreactivity intensity data, and the Tukey HSD test was used as a post hoc analysis.

\section{Results}

All animals survived to the end of the study. Weight loss was statistically significant in all animals $24 \mathrm{~h}$ after the dental movement apparatus was applied. In the following days, the animals gained weight regularly.

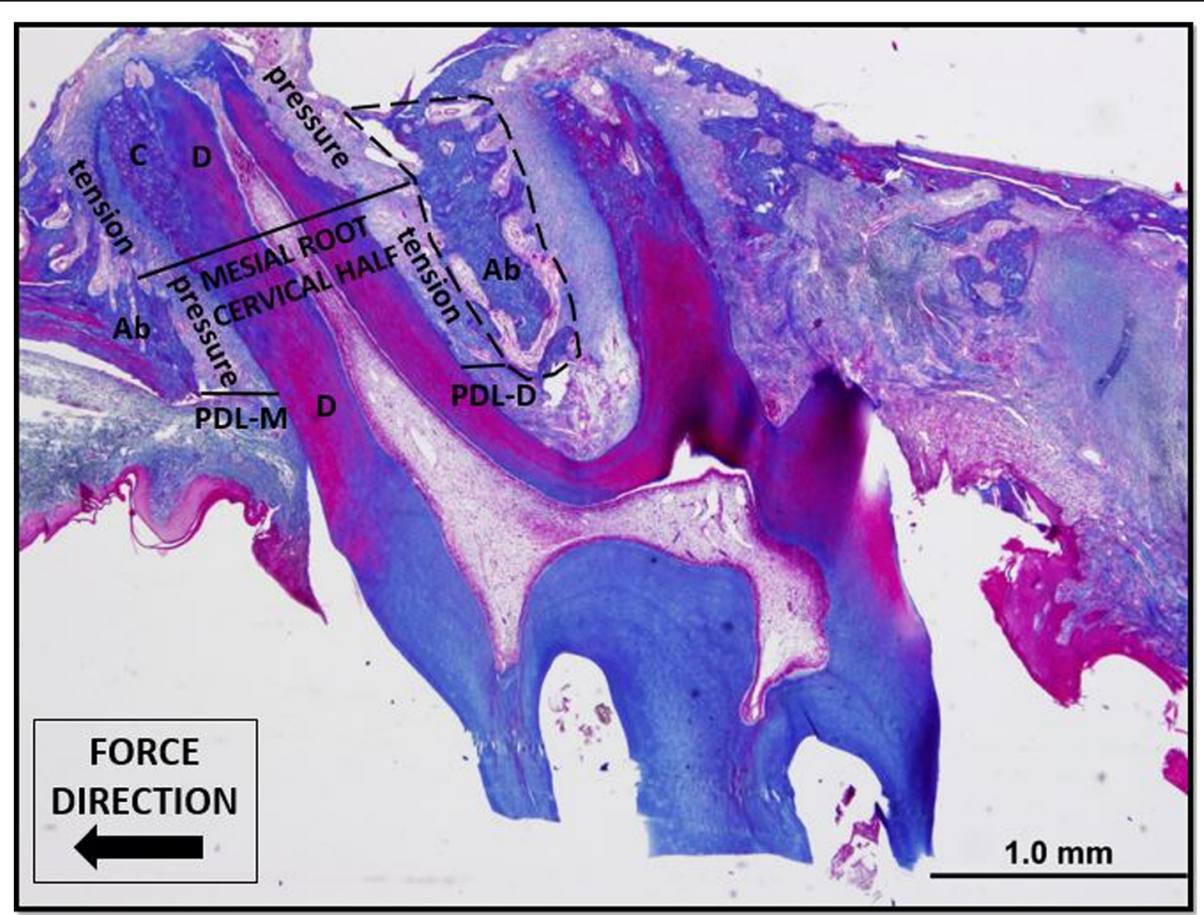

Fig. 4 Demonstration of the PDL distance measurements at $\times 4$ magnification by Masson trichrome staining. The pressure and tension regions of the cervical half of the mesial root where TRAP and ALP immunoreactivity density measurements were made are also shown. The area where the bone area measurement is performed is shown by dashed lines. Ab, alveolar bone; $\mathrm{D}$, dentin; $\mathrm{C}$, cementum 


\section{Amount of the molar mesialization}

Experimental tooth movement was obtained successfully in all groups; there was a statistically significant difference when compared with the negative control group ( $p$ $<0.001)$. The amount of molar mesialization was significantly higher in the $650 \mathrm{~nm}$ LLLT group than in the positive control group $(p=0.017)$ and $405 \mathrm{~nm}$ LLLT group $(p=0.042)$. There was no statistically significant difference between the other groups (Table 1).

\section{PDL distances}

There was a statistically significant difference in PDL-M and PDL-D values between the groups $(p<0.05)$. PDL$\mathrm{M}$ distance was significantly shorter in the negative control group than in all other groups $(p=0.042)$ except for the $532 \mathrm{~nm}$ LLLT group $(p=0.097)$ (Table 2).

PDL-D distance was significantly shorter in the negative control group than in all other groups except for the $940 \mathrm{~nm}$ LLLT group $(p=0.007)$. PDL-D distance was significantly longer in the $532 \mathrm{~nm}(p=0.028)$ and 940 $\mathrm{nm}(p=0.015)$ LLLT groups than in the positive control group. In the $650 \mathrm{~nm}$ LLLT group, it was also significantly longer than in the $940 \mathrm{~nm}$ LLLT group $(p=$ 0.035) (Table 2).

\section{Bone area between the roots}

In terms of the bone area between the roots, there was a statistically significant difference between the groups ( $p$ $<0.05)$. The bone area in the $650 \mathrm{~nm}$ LLLT group was significantly higher than that in the NC $(p=0.022)$ and $405 \mathrm{~nm}$ LLLT $(p=0.036)$ groups. The bone area in the groups $650 \mathrm{~nm}$ LLLT and $940 \mathrm{~nm}$ LLLT was significantly higher than that in the negative control $(p=0.003)$ and $405 \mathrm{~nm}$ LLLT $(p=0.015)$ groups (Table 3$)$.

\section{TRAP staining immunoreactivity intensity}

Histological sections of TRAP staining for each group are shown in Fig. 5. In the measurements of the cervical half of the mesial root after TRAP staining, the mean immunoreactivity intensity in the mesial (TRAP-M) showed a significant difference between the groups $(p=$ $0.002)$. There was no statistically significant difference in the distal side (TRAP-D). The immunoreactivity intensity for TRAP-M was significantly higher in the positive control group than in the $405 \mathrm{~nm}$ LLLT $(p=0.012)$ and $650 \mathrm{~nm}$ LLLT $(p=0.001)$ groups. No significant difference was found between the other groups (Table 4).

\section{ALP staining immunoreactivity intensity}

Histological sections of ALP staining according to groups are shown in Fig. 6. There was no statistically significant difference between the groups in terms of mean immunoreactivity intensity in both mesial and distal measurements in the cervical half of the mesial root after ALP staining $(p<0.05)$ (Table 5).

\section{Discussion}

Our study is the first study to investigate and compare the effect of LLLT of four different wavelengths such as $405 \mathrm{~nm}, 532 \mathrm{~nm}, 650 \mathrm{~nm}$, and $940 \mathrm{~nm}$ on orthodontic tooth movement at the same study. A significant tooth movement was obtained in all groups undergoing orthodontic force, and the amount of molar mesialization was higher in all groups treated with laser than in the nonlaser group. There are several studies in the literature on the effect of LLLT on tooth movement. But, there is no any study investigating the effects of different wavelengths by using the same parameters on tooth movement. The lasers we use in our study had the same parameters other than the wavelengths.

According to the results of a study conducted on rabbits comparing 650-nm and 830-nm wavelengths, laser applications slowed down tooth movement [14]. The visible spectral range has bands equivalent to three primary colors: blue $(380-440 \mathrm{~nm})$, green $(440-600 \mathrm{~nm})$, and red $(600-750 \mathrm{~nm})$; near-infrared range $(750-1100 \mathrm{~nm})$ and

Table 1 Evaluation of the amount of molar mesialization between the groups $(\mathrm{mm})$

\begin{tabular}{|c|c|c|c|c|c|c|c|c|c|c|c|c|c|c|c|}
\hline \multirow{2}{*}{$\begin{array}{l}\text { Group/ } \\
\text { variable }\end{array}$} & \multicolumn{6}{|c|}{ Molar mesialization (mm) } & \multicolumn{7}{|c|}{ 95\% confidence interval for mean } & \multirow{2}{*}{\multicolumn{2}{|c|}{$p$}} \\
\hline & \multicolumn{3}{|l|}{ Mean } & \multicolumn{3}{|l|}{ S.D. } & \multicolumn{4}{|c|}{ Lower bound } & \multicolumn{3}{|c|}{ Upper bound } & & \\
\hline NC & 0.000 & & & 0.000 & & & 0.000 & & & & 0.000 & & & $<0.001^{*}$ & \\
\hline PC & 0.467 & & & 0.357 & & & 0.192 & & & & 0.741 & & & & \\
\hline $405 \mathrm{~nm}$ & 0.644 & & & 0.261 & & & 0.443 & & & & 0.845 & & & & \\
\hline $532 \mathrm{~nm}$ & 0.731 & & & 0.173 & & & 0.598 & & & & 0.864 & & & & \\
\hline $650 \mathrm{~mm}$ & 0.878 & & & 0.201 & & & 0.724 & & & & 1.032 & & & & \\
\hline $940 \mathrm{~nm}$ & 0.723 & & & 0.230 & & & 0.559 & & & & 0.887 & & & & \\
\hline \multicolumn{16}{|c|}{ Pairwise comparisons, $p$ values } \\
\hline \multirow[t]{2}{*}{ MM } & NC-PC & $\begin{array}{l}\text { NC- } \\
405 \mathrm{~nm}\end{array}$ & $\begin{array}{l}\text { NC- } \\
532 \mathrm{~nm}\end{array}$ & $\begin{array}{l}\text { NC- } \\
650 \mathrm{~nm}\end{array}$ & $\begin{array}{l}\text { NC- } \\
940 \mathrm{~nm}\end{array}$ & $\begin{array}{l}\text { PC- } \\
405 \mathrm{~nm}\end{array}$ & $\begin{array}{l}\text { PC- } \\
532 \mathrm{~nm}\end{array}$ & $\begin{array}{l}\text { PC- } \\
650 \mathrm{~nm}\end{array}$ & $\begin{array}{l}\text { PC-940 } \\
\mathrm{nm}\end{array}$ & $\begin{array}{l}405-532 \\
\mathrm{~nm}\end{array}$ & $\begin{array}{l}405-650 \\
\mathrm{~nm}\end{array}$ & $\begin{array}{l}405-940 \\
\mathrm{~nm}\end{array}$ & $\begin{array}{l}532-650 \\
\mathrm{~nm}\end{array}$ & $\begin{array}{l}532-940 \\
\mathrm{~nm}\end{array}$ & $\begin{array}{l}650-940 \\
\mathrm{~nm}\end{array}$ \\
\hline & $0.000 *$ & $0.000 *$ & $0.000^{*}$ & $0.000 *$ & $0.000^{*}$ & 0.331 & 0.070 & $0.017^{*}$ & 0.165 & 0.251 & $0.042^{*}$ & 0.462 & 0.270 & 0.513 & 0.683 \\
\hline
\end{tabular}

MM amount of molar mesialization, NC negative control group, $P C$ positive control group, S.D. standard deviation Significant degree: ${ }^{*} p<0.05$ 


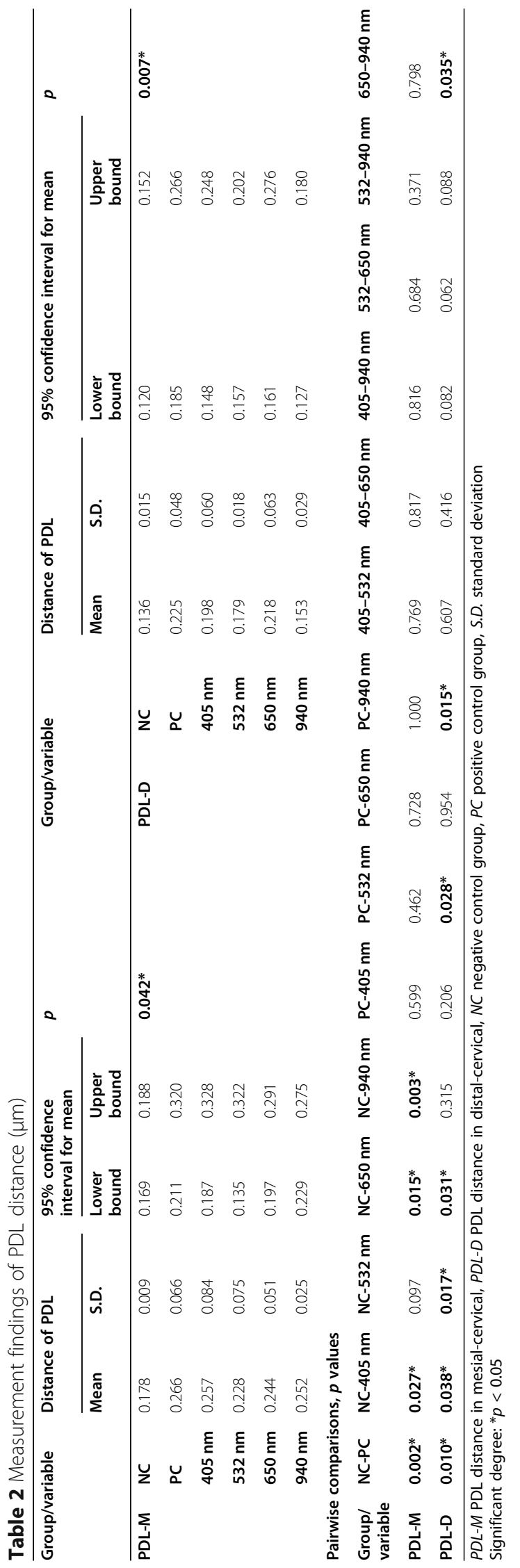


Table 3 Findings of the bone area measurement between the roots $\left(\mu \mathrm{m}^{2}\right)$

\begin{tabular}{|c|c|c|c|c|c|c|c|c|c|c|c|c|c|c|c|}
\hline \multirow{2}{*}{$\begin{array}{l}\text { Group/ } \\
\text { variable }\end{array}$} & \multicolumn{6}{|c|}{ The bone area (BA) } & \multicolumn{7}{|c|}{$95 \%$ confidence interval for mean } & \multirow{2}{*}{\multicolumn{2}{|c|}{$p$}} \\
\hline & \multicolumn{3}{|l|}{ Mean } & \multicolumn{3}{|l|}{ S.D. } & \multicolumn{4}{|c|}{ Lower bound } & \multicolumn{3}{|c|}{ Upper bound } & & \\
\hline NC & 0.351 & & & 0.059 & & & 0.289 & & & & 0.413 & & & $0.020^{*}$ & \\
\hline PC & 0.467 & & & 0.135 & & & 0.354 & & & & 0.581 & & & & \\
\hline $405 \mathrm{~nm}$ & 0.407 & & & 0.090 & & & 0.332 & & & & 0.483 & & & & \\
\hline $532 \mathrm{~nm}$ & 0.447 & & & 0.106 & & & 0.316 & & & & 0.579 & & & & \\
\hline $650 \mathrm{~mm}$ & 0.502 & & & 0.098 & & & 0.411 & & & & 0.593 & & & & \\
\hline $940 \mathrm{~nm}$ & 0.594 & & & 0.124 & & & 0.480 & & & & 0.709 & & & & \\
\hline \multicolumn{16}{|c|}{ Pairwise comparisons, $p$ values } \\
\hline \multirow[t]{2}{*}{ BA } & $\begin{array}{l}\text { NC- } \\
\text { PC }\end{array}$ & $\begin{array}{l}\text { NC- } \\
405 \\
\mathrm{~nm}\end{array}$ & $\begin{array}{l}\text { NC- } \\
532 \\
\mathrm{~nm}\end{array}$ & $\begin{array}{l}\text { NC- } \\
650 \\
\mathrm{~nm}\end{array}$ & $\begin{array}{l}\text { NC- } \\
940 \\
\mathrm{~nm}\end{array}$ & $\begin{array}{l}\text { PC- } \\
405 \\
\mathrm{~nm}\end{array}$ & $\begin{array}{l}\text { PC- } \\
532 \\
\mathrm{~nm}\end{array}$ & $\begin{array}{l}\text { PC- } \\
650 \\
\mathrm{~nm}\end{array}$ & $\begin{array}{l}\text { PC- } \\
940 \\
\mathrm{~nm}\end{array}$ & $\begin{array}{l}405- \\
532 \mathrm{~nm}\end{array}$ & $\begin{array}{l}405- \\
650 \mathrm{~nm}\end{array}$ & $\begin{array}{l}405- \\
940 \mathrm{~nm}\end{array}$ & $\begin{array}{l}532- \\
650 \mathrm{~nm}\end{array}$ & $\begin{array}{l}532- \\
940 \mathrm{~nm}\end{array}$ & $\begin{array}{l}650- \\
940 \mathrm{~nm}\end{array}$ \\
\hline & 0.244 & 0.604 & 0.066 & $0.022^{*}$ & $0.003^{*}$ & 0.247 & 0.557 & 0.486 & 0.104 & 0.768 & $0.036^{*}$ & $0.015^{*}$ & 0.368 & 0.120 & 0.108 \\
\hline
\end{tabular}

$B A$ bone area between the roots, NC negative control group, $P C$ positive control group, S.D. standard deviation Significant degree: ${ }^{*} p<0.05$

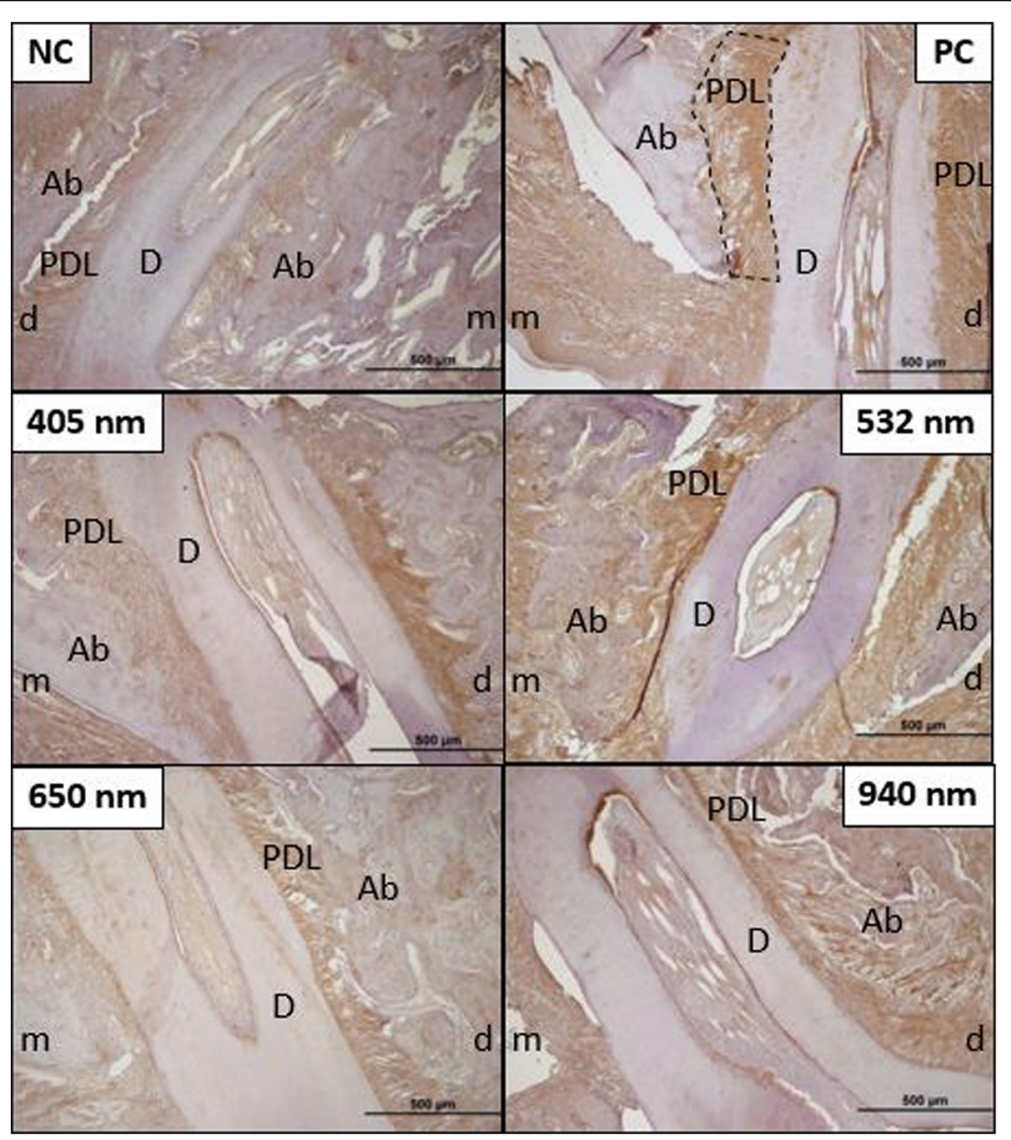

Fig. 5 Preparations using the immunohistochemistry staining method with TRAP primary antibody for immunoreactivity intensity are shown in $x$ 10 magnification. The black dashed line is marked to show the area of PDL in which the immunoreactivity measurement is performed (NC, negative control group; PC, positive control group; B, 405 nm LLLT group; C, $532 \mathrm{~nm}$ LLLT group; D, $650 \mathrm{~nm}$ LLLT group; E, $940 \mathrm{~nm}$ LLLT group; $\mathrm{m}$, mesial; d, distal; PDL, periodontal ligament; Ab, alveolar bone; D, dentin) 


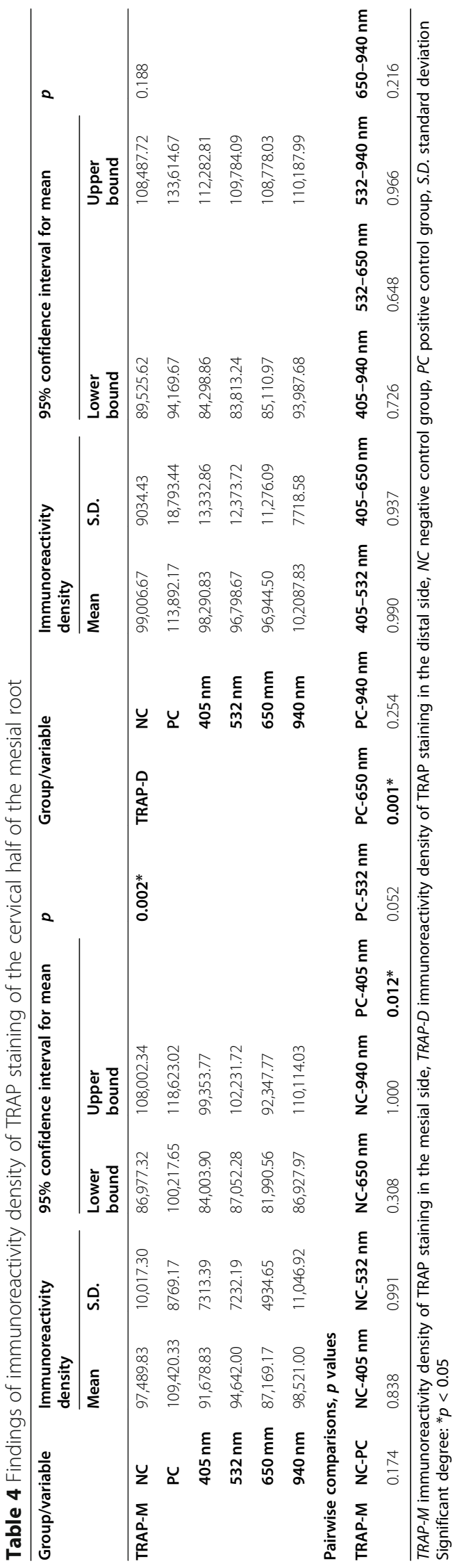




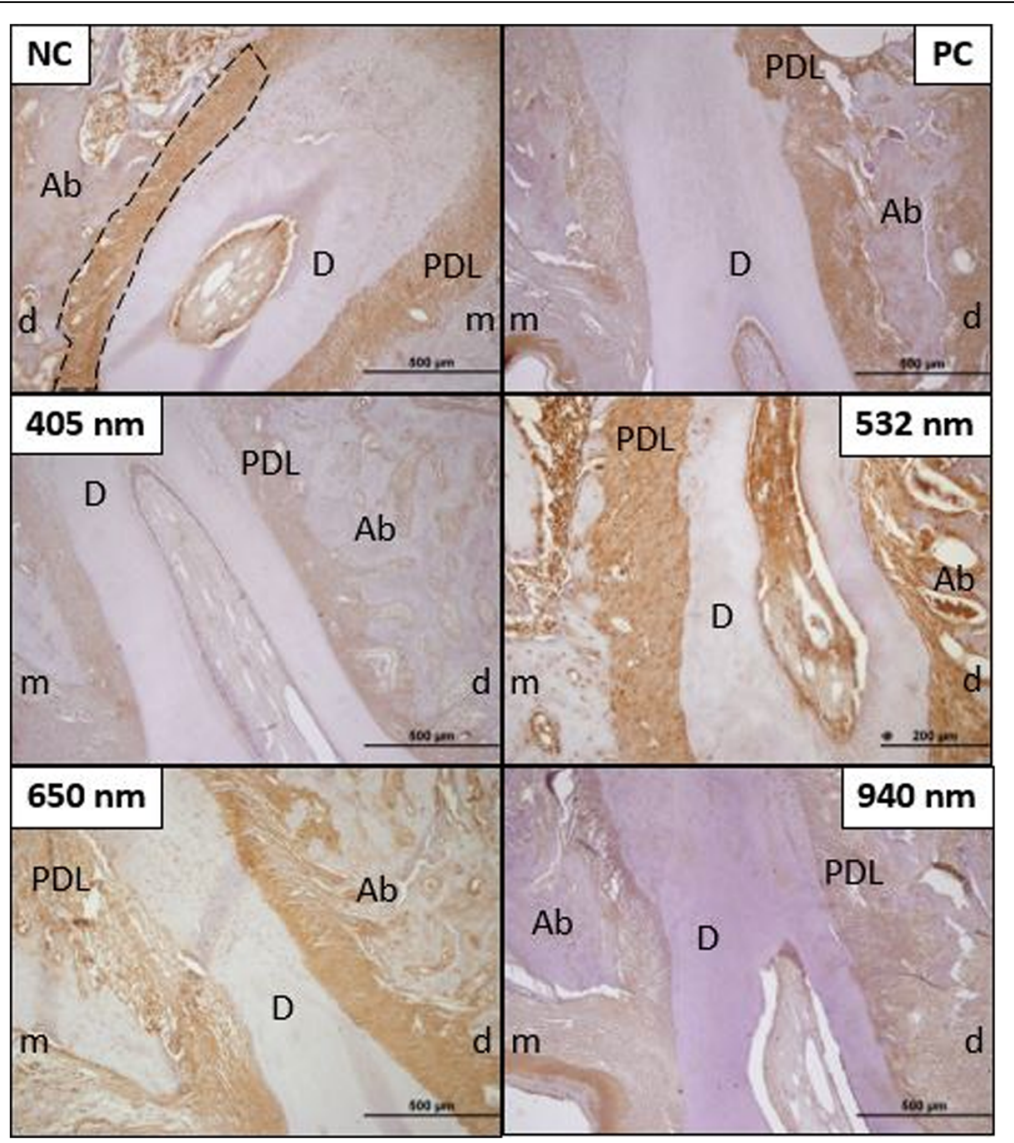

Fig. 6 Preparations using the immunohistochemistry staining method with ALP primary antibody for immunoreactivity intensity are shown in $x$ 10 magnification. The black dashed line is marked to show the area of PDL in which the immunoreactivity measurement is performed (NC, negative control group; PC, positive control group; B, 405 nm LLLT group; C, 532 nm LLLT group; D, 650 nm LLLT group; E, 940 nm LLLT group; m, mesial; d, distal; PDL, periodontal ligament; Ab, alveolar bone; D, dentin)

short-wave infrared range $(1550-2400 \mathrm{~nm})$ [19]. Although the penetration depths of lasers of these wavelengths on the skin are similar, lasers with colors nearinfrared can reach a little deeper [20]. Still, it is not easy to estimate the depth of penetration on structures such as the gums, alveolar bone, and periodontal ligament in the mouth.

There are many studies in the literature showing that between 780- and 830-nm wavelengths of the GaAlAs diode laser, which is near-infrared, accelerate orthodontic tooth movement $[8,13,21]$. The number of studies performed with diode lasers with $650-\mathrm{nm}$ and $940-\mathrm{nm}$ wavelengths that we used in our study is less, and there are no other studies comparing them with each other under the same conditions. Therefore, we preferred diode lasers with wavelengths of $650 \mathrm{~nm}$ (red) and 940 $\mathrm{nm}$ (near-infrared), which have been less studied in the literature. Our results showed that 650-nm LLLT significantly increased the amount of molar mesialization compared to the groups treated with only orthodontic tooth movement and 405-nm LLLT. Since the laser at 940-nm wavelength is in the same group with the near-infrared lasers used in the other studies, it is thought to have a similar effect with them. In addition, Esnouf et al. reported that the $850-\mathrm{nm}$ laser with $100-\mathrm{mW}$ output power lost $66 \%$ of its power after $1 \mathrm{~mm}$ penetration [22]. Therefore, it is estimated that 650 -nm LLLT may have similar effects on orthodontic tooth movement with GaAlAs diode lasers with wavelengths of approximately $800 \mathrm{~nm}$ used in some other studies or may be relatively more effective due to less energy loss during tissue penetration.

PDL distance varies according to the remodeling stage. As a result of the orthodontic force applied, the PDL distance on the pressure side decreases first, later increases when the alveolar bone resorption begins. Brudvick and Rygh [23] reported that the PDL distance on the side of the pressure started to return to normal size on the 7th day after the orthodontic force was applied. In our study, similar to the literature, the PDL distance on the pressure side (PDL-M) of all groups with tooth movement was significantly higher than that of the 


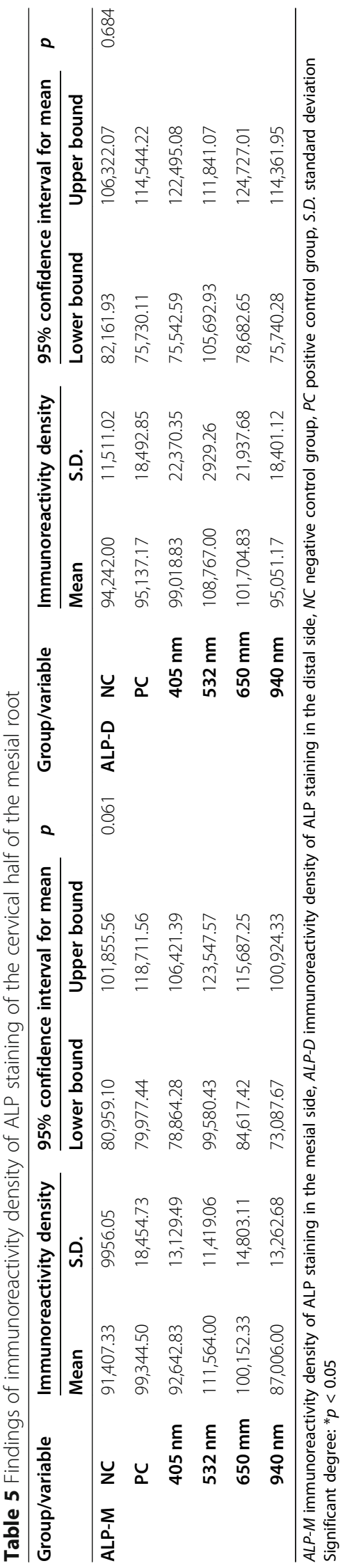


negative control group. There was no significant difference between the negative control group and the 532 $\mathrm{nm}$ laser group. In the PDL-D region, PDL distance in all groups except the $940 \mathrm{~nm}$ LLLT group was significantly higher than that in the negative control group. The PDL distance in groups $532 \mathrm{~nm}$ LLLT and $940 \mathrm{~nm}$ LLLT is also shorter than the PC group. Wang et al. [24] stated that the $540 \mathrm{~nm}$ LED light increases RUNX-2 expression, and $420 \mathrm{~nm}, 660 \mathrm{~nm}$, and $810 \mathrm{~nm}$ wavelength groups are not significantly different from each other. RUNX-2 functions to direct multipotent mesenchymal stem cells to skeletal chondrocyte/osteoblast cells. In addition, RUNX-2 also plays a role in limiting the terminal differentiation of osteoblasts to osteocytes, thus maintaining the number of active osteoblasts [25]. Considering the results of Wang et al., 532-nm LLLT may have increased osteoblastic activity more than LLLTs of other wavelengths. Similarly, 940-nm LLLT was thought to increase osteoblastic activity, although not as much as 532-nm LLLT. The PDL distance in the $940 \mathrm{~nm}$ LLLT group was significantly shorter than that in the $650 \mathrm{~nm}$ LLLT group. The amount of molar mesialization in the $650 \mathrm{~nm}$ LLLT group was greater than that in the $940 \mathrm{~nm}$ LLLT group (and all other groups). Therefore, both the tension and the distance in the PDL-D region are probably higher than the other laser groups. Even if the healing potentials (osteogenesis) of all LLLTs are the same, it is thought that it may take more time for the distance to return to its normal state in the $650 \mathrm{~nm}$ LLLT group, since the largest distance is in this group. PDL distance measurements in our study were performed on the 14th day, when the PDL was partially normalized.

Kawasaki and Shimizu reported that the $830 \mathrm{~nm}$ LLLT group applied during the experimental tooth movement reported that the newly formed bone area on the tension side is more than the control group [21]. Merli et al. investigated the effects of 670-nm LLLT on wound healing of the mouse femoral bone. At the end of the 14-day trial period, they reported that the newly formed bone in the laser group had more space and intensity than that in the control group [26]. Kushibiki et al. [27] investigated the effects of lasers of $405 \mathrm{~nm}$ (blue), $664 \mathrm{~nm}$ (red), and $808 \mathrm{~nm}$ (infrared) on 10 different cell types. They reported that intracellular reactive oxygen radicals increased in 405-nm light cells, and there was no difference in other groups. In another study conducted in vitro with 635-nm LED light, it was found that LED application reduced osteoclastogenesis by lowering intracellular reactive oxygen radicals. Therefore, it has been reported that there may be a conservative alternative treatment approach in osteoporosis treatment [28]. The bone area observed in our study was significantly higher in the $650 \mathrm{~nm}$ and $940 \mathrm{~nm}$ LLLT groups than in the negative control and $405 \mathrm{~nm}$ LLLT groups. Our findings are consistent with the previous literature.
The occurrence of orthodontic tooth movement depends on the release of osteoclasts and precursor cells, osteoclast differentiation, and the intensity of osteoclast activity on the surface of bone-PDL, depending on the individual's resorption potential. Fujita et al. [8] studied the effects of 810-nm laser and 830-nm LED (light-emitting diode) on tooth movement. The pressure side in the laser group reported that the intensity of TRAP immunoreactivity in PDL was higher on the 2nd, 3rd, 4th, and 7 th days than in the LED and control group. In our study, we did not see the stage of intense osteoclastic cell forming in the initial tooth movement because we sacrificed the subjects on day 14 . There was no statistically significant difference on the distal side in terms of TRAP immunoreactivity intensity. Since we do not expect osteoclastic activity in the tension region, this finding is consistent with the literature. The intensity of immunoreactivity for TRAP in the mesial side is less in all laser groups than in the PC group and closer to the values in the $\mathrm{NC}$ group; in other words, osteoclastic activity on day 14 in laser groups is less than in the PC group. But only the difference between the $405 \mathrm{~nm}$ and $650 \mathrm{~nm}$ LLLT groups and the PC group is significant. It is thought that osteoclastic activity was stimulated at an earlier stage in the LLLT groups than in the PC group, and similarly, bone turnover may have started earlier than in the PC group.

The verification of the production of ALP indicates that the osteoblast differentiation has started [29]. Kushibiki and Awazu [30] investigated the effects of 405-nm light on osteogenesis. According to the results of the study, ALP activity, calcium, and calcium phosphate accumulation increased 5 days after laser application.

Kim et al. [31] reported that exposure of 647-nm red light on mouse mesenchymal stem cells which were cultured in the presence of osteogenic differentiation medium for 3 days promotes osteoblastic differentiation significantly. Jawad et al. [32], according to the results of their in vitro study with the laser at $940 \mathrm{~nm}$ wavelength, stated there was an increased ALP activity in the laser applied group compared to the control group. They reported that LLLT at $940 \mathrm{~nm}$ wavelength can contribute to the bone formation by stimulating osteoblast cells.

In our study, there was no statistically significant difference between the groups in terms of ALP immunoreactivity intensity in both mesial and distal. In studies in the literature, since the evaluations are generally made between the 1st and 7th days, ALP activity is increased, whereas in our study, it is thought that there is no difference because the evaluations are done on the 14th day.

\section{Limitations}

It is known that tooth movement consists of several phases. Lee reported that $6 \mathrm{~h}$ after the application of 
force, the width of the PDL decreased on the pressure side, deformation was seen in the fibroblasts, the number of Howship's lacunae increased, and the hyalinization tissue disappeared on the 3rd day [33]. Radunovic et al. Reported that the most active "remodeling" response was seen 7 days after the force was applied [34].

Since we wanted to investigate the effect of low-level lasers of different wavelengths on the amount of orthodontic tooth movement in our study, the subjects were sacrificed only at the end of the 14th day. Therefore, the histological and immunohistochemical data obtained show the results at the stage when periodontal tissues partially normalize. The data to be obtained as a result of the sacrifices to be performed on the 3rd and 7th days of the orthodontic force application might provide more detailed information especially about PDL distance and bone turnover.

\section{Conclusions}

The results of this study show that LLLT with $650-\mathrm{nm}$ wavelength increases orthodontic tooth movement more than 405-nm, 532-nm, and 940-nm LLLTs. The 940-nm and $650-\mathrm{nm}$ LLLT also increases the bone area between the roots by more than $405-\mathrm{nm}$ and $532-\mathrm{nm}$ wavelengths.

\section{Abbreviations \\ LLLTs: Low-level laser therapies; PDL: Periodontal ligament; TRAP: Tartrate- resistant acid phosphatase; ALP: Alkaline phosphatase; Cl: Confidence interval; ATP: Adenosine triphosphate; NO: Nitric oxide; ROS: Reactive oxygen species; IL1-ß: Interleukin 1 beta; IL-6: Interleukin 6; TNF-a: Tumor necrosis factor alpha; RANKL: Receptor activator of nuclear factor kappa-B ligand; RANK: Receptor activator of nuclear factor kappa-B; LED: Light-emitting diode; RUNX-2: Runt-related protein 2}

\section{Acknowledgements}

Not applicable

\section{Authors' contributions}

HBK performed the study on the subjects. AHY and OG performed the histological examination. AY analyzed the data of the study. In addition, HBK and $A Y$ were the major contributors in writing the manuscript. All authors read and approved the final manuscript.

\section{Funding}

This work was supported by the Erciyes University Scientific Research Projects Coordination Unit (Project code: TDH-2018-8141).

\section{Availability of data and materials}

All data generated or analyzed during this study are included in this published article.

\section{Ethics approval and consent to participate}

All applicable international, national, and/or institutional guidelines for the care and use of animals were followed. All procedures performed in studies involving animals were in accordance with the ethical standards of the Erciyes University Animal Experiments Local Ethics Committee commission (approval code: 17/128).

\section{Consent for publication}

Not applicable

\section{Competing interests}

The authors declare that they have no competing interests.

\section{Author details}

${ }^{1}$ Eskisehir Oral and Dental Health Hospital, Yenikent, Piri Reis St. No. 28, Odunpazarı, 26050 Eskisehir, Turkey. ${ }^{2}$ Department of Orthodontics, Faculty of Dentistry, Erciyes University, Kayseri, Turkey. ${ }^{3}$ Department of Histology and Embryology, Faculty of Medicine, Erciyes University, Kayseri, Turkey. ${ }^{4}$ Genome and Stem Cell Center (GENKOK), Erciyes University, Kayseri, Turkey.

Received: 30 May 2020 Accepted: 5 November 2020

Published online: 01 December 2020

\section{References}

1. Skidmore KJ, Brook KJ, Thomson WM, Harding WJ. Factors influencing treatment time in orthodontic patients. Am J Orthod Dentofac Orthop. 2006;129(2):230-8.

2. Shenava S, Nayak K, Bhaskar V, Nayak A. Accelerated orthodontics-a review. Intern J Sci Study. 2014;1(5):35-9.

3. Sekhavat AR, Mousavizadeh K, Pakshir HR, Aslani FS. Effect of misoprostol, a prostaglandin E1 analog, on orthodontic tooth movement in rats. Am J Orthod Dentofac Orthop. 2002;122(5):542-7.

4. Bartzela T, Türp JC, Motschall E, Maltha JC. Medication effects on the rate of orthodontic tooth movement: a systematic literature review. Am J Orthod Dentofac Orthop. 2009;135(1):16-26.

5. Borzabadi-Farahani A, Cronshaw M. Lasers in orthodontics. In: Lasers in dentistry_current concepts. Berlin: Springer; 2017. p. 247-71.

6. Bjordal JM, Johnson MI, Iversen V, Aimbire F, Lopes-Martins RAB. Low-level laser therapy in acute pain: a systematic review of possible mechanisms of action and clinical effects in randomized placebo-controlled trials. Photomed Laser Surg. 2006;24(2):158-68.

7. Walsh MC, Choi Y. Biology of the RANKL-RANK-OPG system in immunity, bone, and beyond. Front Immunol. 2014;5:511.

8. Fujita S, Yamaguchi M, Utsunomiya T, Yamamoto H, Kasai K. Low-energy laser stimulates tooth movement velocity via expression of RANK and RANK L. Orthod Craniofacial Res. 2008;11(3):143-55.

9. da Silva Sousa MV, Scanavini MA, Sannomiya EK, Velasco LG, Angelieri F. Influence of low-level laser on the speed of orthodontic movement. Photomed Laser Surg. 2011;29(3):191-6.

10. Gkantidis N, Mistakidis I, Kouskoura T, Pandis N. Effectiveness of nonconventional methods for accelerated orthodontic tooth movement: a systematic review and meta-analysis. J Dent. 2014;42(10):1300-19.

11. Kalemaj Z, Debernardl CL, Buti J. Efficacy of surgical and non-surgical interventions on accelerating orthodontic tooth movement: a systematic review. Eur J Oral Implantol. 2015;8(1):9-24.

12. Cruz DR, Kohara EK, Ribeiro MS, Wetter NU. Effects of low-intensity laser therapy on the orthodontic movement velocity of human teeth: a preliminary study. Lasers Surg Med. 2004;35(2):117-20.

13. Yoshida T, Yamaguchi M, Utsunomiya T, Kato M, Arai Y, Kaneda T, Yamamoto H, Kasai K. Low-energy laser irradiation accelerates the velocity of tooth movement via stimulation of the alveolar bone remodeling. Orthod Craniofacial Res. 2009;12(4):289-98.

14. Seifi M, Shafeei HA, Daneshdoost S, Mir M. Effects of two types of low-level laser wave lengths ( 850 and $630 \mathrm{~nm}$ ) on the orthodontic tooth movements in rabbits. Lasers Med Sci. 2007;22(4):261-4.

15. Koçoğlu-Altan B, Sökücü O. The effects of Nd:YAG laser on maxillary canine distalization rate. Turk J Orthod. 2009;22:16-25.

16. Ben-David D, Srouji S, Shapira-Schweitzer K, Kossover O, Ivanir E, Kuhn G, Müller R, Seliktar D, Livne E. Low dose BMP-2 treatment for bone repair using a PEGylated fibrinogen hydrogel matrix. Biomaterials. 2013;34(12): 2902-10.

17. Moutsatsos IK, Turgeman G, Zhou S, Kurkalli BG, Pelled G, Tzur L, Kelley P, Stumm N, Mi S, Müller R. Exogenously regulated stem cell-mediated gene therapy for bone regeneration. Mol Ther. 2001;3(4):449-61.

18. Yay A, Onses MS, Sahmetlioglu E, Ceyhan A, Pekdemir S, Onder GO, Sezer G, Soyer Sarica Z, Aydin F. Raman spectroscopy: a novel experimental approach to evaluating cisplatin induced tissue damage. Talanta. 2020;207: 120343.

19. Liu J. G. REMOTE SENSING I Passive Sensors. Reference module in earth systems and environmental sciences. In: Encyclopedia of geology; 2013. p. 431-9.

20. Avci P, Gupta A, Sadasivam M, Vecchio D, Pam Z, Pam N, Hamblin MR. Lowlevel laser (light) therapy (LLLT) in skin: stimulating, healing, restoring. In: 
Seminars in cutaneous medicine and surgery, vol. 1: NIH Public Access; 2013. p. 41.

21. Kawasaki K, Shimizu N. Effects of low-energy laser irradiation on bone remodeling during experimental tooth movement in rats. Lasers Surg Med. 2000;26(3):282-91.

22. Esnouf A, Wright PA, Moore JC, Ahmed S. Depth of penetration of an 850 $\mathrm{nm}$ wavelength low level laser in human skin. Acupunct Electrother Res. 2007;32(1-2):81-6.

23. Brudvik P, Rygh P. Transition and determinants of orthodontic root resorption-repair sequence. Eur J Orthod. 1995;17(3):177-88.

24. Wang $Y$, Huang $Y-Y$, Wang $Y$, Lyu P, Hamblin MR. Photobiomodulation (blue and green light) encourages osteoblastic-differentiation of human adiposederived stem cells: role of intracellular calcium and light-gated ion channels. Sci Rep. 2016;6:33719.

25. Stadler HS, Higgins KM, Capecchi MR. Loss of Eph-receptor expression correlates with loss of cell adhesion and chondrogenic capacity in Hoxa13 mutant limbs. Development. 2001;128(21):4177-88.

26. Merli LADS, Santos MTBRD, Genovese WJ, Faloppa F. Effect of low-intensity laser irradiation on the process of bone repair. Photomed Laser Surg. 2005; 23(2):212-5.

27. Kushibiki T, Hirasawa T, Okawa S, Ishihara M. Blue laser irradiation generates intracellular reactive oxygen species in various types of cells. Photomed Laser Surg. 2013;31(3):95-104.

28. Sohn H, Ko Y, Park M, Kim D, Moon YL, Jeong YJ, et al. Effects of lightemitting diode irradiation on RANKL-induced osteoclastogenesis. Lasers Surg Med. 2015;47(9):745-55.

29. Inoue A, Hatayama H, Suganuma H, Awazu K, Kushibiki T. Method of differentiation induction to osteoblasts. 2010. Washington, DC. U.S. Patent No. 7,829,335

30. Kushibiki T, Awazu K. Controlling osteogenesis and adipogenesis of mesenchymal stromal cells by regulating a circadian clock protein with laser irradiation. Int J Med Sci. 2008;5(6):319.

31. Kim HK, Kim JH, Abbas AA, Kim D-O, Park S-J, Chung JY, Song EK, Yoon TR Red light of $647 \mathrm{~nm}$ enhances osteogenic differentiation in mesenchymal stem cells. Lasers Med Sci. 2009;24(2):214-22.

32. Jawad MM, Husein A, Azlina A, Alam MK, Hassan R, Shaari R. Effect of 940 nm low-level laser therapy on osteogenesis in vitro. J Biomed Opt. 2013; 18(12):128001.

33. Lee W. Experimental study of the effect of prostaglandin administration on tooth movement-with particular emphasis on the relationship to the method of PGE1 administration. Am J Orthod Dentofac Orthop. 1990;98(3): 231-41.

34. Vandevska-Radunovic V, Kvinnsland S, Kvinnsland IH. Effect of experimental tooth movement on nerve fibres immunoreactive to calcitonin gene-related peptide, protein gene product 9.5, and blood vessel density and distribution in rats. Eur J Orthod. 1997;19(5):517-29.

\section{Publisher's Note}

Springer Nature remains neutral with regard to jurisdictional claims in published maps and institutional affiliations.

\section{Submit your manuscript to a SpringerOpen ${ }^{\circ}$ journal and benefit from:}

- Convenient online submission

- Rigorous peer review

- Open access: articles freely available online

- High visibility within the field

- Retaining the copyright to your article

Submit your next manuscript at $\boldsymbol{\nabla}$ springeropen.com 